\title{
دور إستر اتيجية التعليم المتمايز \\ في زيادة التحصيل الموسيقي لطلاب المرحلة الثانوية
}

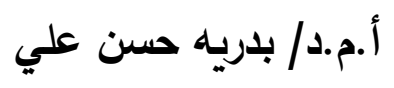

أستاذ المناهج وطرق تدريس التربية الموسيقية المساعد

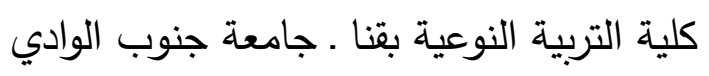

أ / أ منال حسن إسماعيل

باحث لدرجة الماجستير

كلية التربية النوعية بقنا لتاهيت

جامعة جنوب الوادي
أ.م. د/ كريمة رمضان أبو زيد

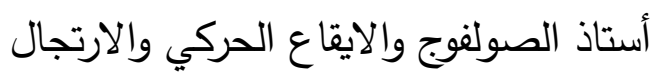

كلية التربية النوعية بقنا

جامعة جنوب الوادي 


\section{المستخلص}

تحددت مشكلة البحث في السؤال الرئيس ما فاعلية استخدام الحاسب الآلي في تتمية

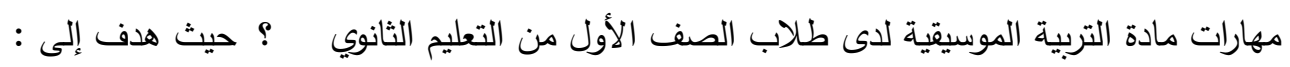

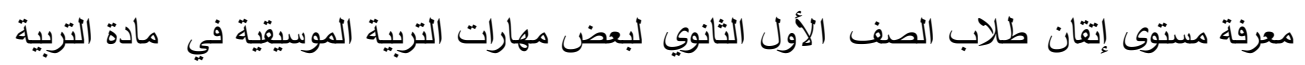

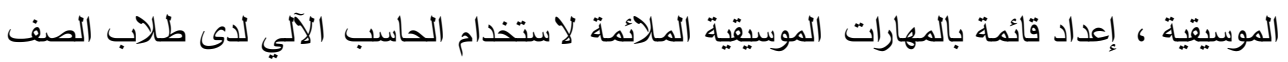

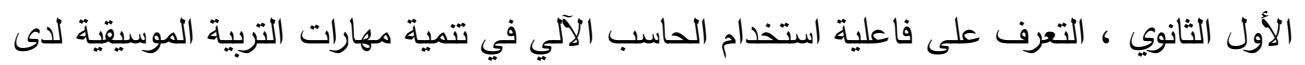
طلاب الصف الأول الثانوي ـ كما اتبعت الباحثة المنهج التجريبي، وتكونت عينة الرحث من (20)

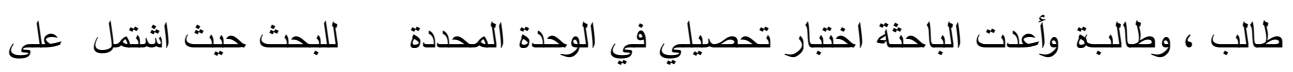

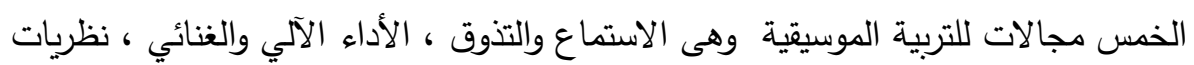

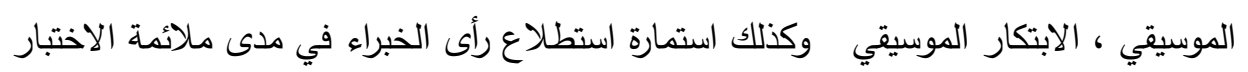

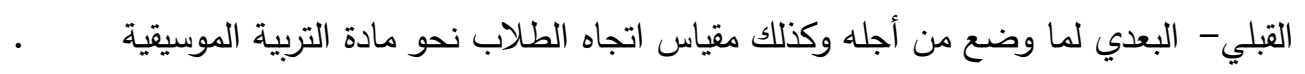

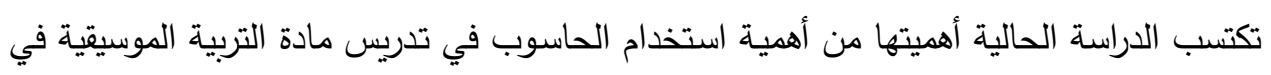

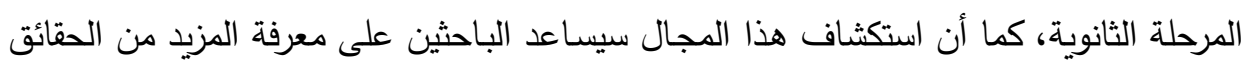

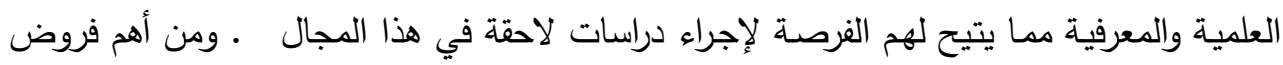

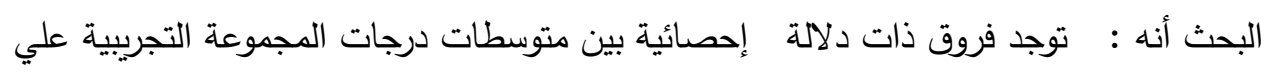

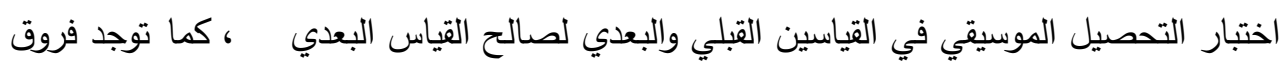
ذات دلالة إحصائية بين متوسطات درجات المجموعة التجريبية لمقياس الاتجاه نحو مادة التربية

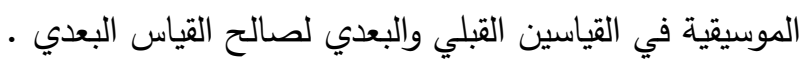
الكلمات المفتاحية : استراتيجية التعليم المتمايز ـ زيادة التحصيل الموسيقى 


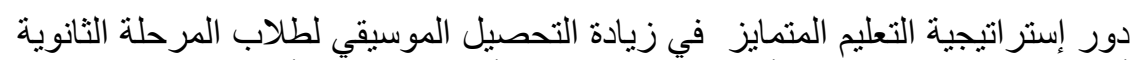

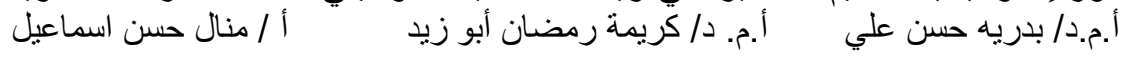

\title{
The Effectiveness of Using Differntiation Strategies in Developing the Skills of Music Education for First Year Secondary School Students
}

\author{
Prof .Dr . Badria Hassan Ali Prof Dr. Karima Ramadan Abuzied \\ Manal Hassan Ismaiel
}

\begin{abstract}
Problem of the study could be stated in the main question, namely; What is the effectiveness of using computer in developing the skills of music education for first year secondary school students? This research aimed to determine the level of first year secondary school students' proficiency of some music skills, to prepare a list of musical skills suitable for using computers for first year secondary school students, to investigate the effectiveness of using computer in developing the skills of music education for first year secondary school students. The experimental design was used. The sample consisted of 20 students (males and females). The researcher prepared an achievement test for the targeted unit. The test included five areas of musical education: listening and feeling the music, musical performance and singing, music theories, and musical creation. A questionnaire for measuring the students attitudes towards the subject was also prepared. The test and the questionnaire were checked by a jury of experts for appropriateness. Significance of the present study could be determined in light of the importance of using computers in teaching music education in the secondary stage. Besides, exploring this area might help other researchers to learn more scientific and cognitive facts, which gives them the opportunity to conduct further studies in this field. Concerning the study results, the following hypotheses were formulated: There were statistically significant differences between the mean scores of the experimental group on the pre-post administration of the musical achievement test, favoring the experimental group. Further, there were statistically significant differences between the mean scores of the experimental group of the attitudes questionnaire towards the music education in the pre-post administration in favor of the post measurement.
\end{abstract}

Keywords: Differntiation Strategies, Skills of Music Education 
يعد التعليم الركيزة الأولي للتقدم و الأساس اللازم لمسايرة التطور فمن خلاله يتت توجيه واستثمار الموارد البشرية بشكل فعال لتزويد الإنسان بالقيم الدينية والسلوكيات المعرفية والتخصصية في شتى المجالات حتى يصبح الإنسان مهيأ للمساهمة في بناء المجتمع ودفعه الي كل ما هو جديد ولقد تتافس التربويون في إيجاد طرق حديثة و متتوعة ؛ لضمان جودة مخرجات التعليم،

نظراً لأن مخرجات التعليم لا تتناسب مع مدخلاته وهذه المشكلة واضحة في أغلب المدارس ، فئل فالجهود المبذولة في مجال التعليم كبيرة ، والوقت المخصص لها طويل ، والنفقات باهظة ، ولكن تأتي النتائج هزيلة )توفيق أحمد مرعي، ححم محمود ،2002 م ، ص 24 ) . حيث يعود ذلك إلى أن طرق التدريس المعتادة تركز على المادة العلمية ، وتهمل المتعلم؛ فيصبح التعلم عبارة عن حفظ مجموعة من المعارف والمعلومات مما يجعل المتعلم سلبياً يعتمد على الحفظ الآلي ، ويعطيه أهمية كبيرة ويركز جهده على السيطرة على المادة بهدف الاحتفاظ بها واسترجاعها عند الحاجة إليها ؛ واحتلت العملية التعليمية مكاناً بارزاً ضمن آليات التطوير باعتبارها عملية تتناول جميع الجوانب الشخصية للمتعلم ولذلك تسعي المؤسسات التعليمية إلي تحقيق الهدف والغاية من العملية التعليمية بدرجة عالية من الكفاءة والإتقان والاهتمام بالفرد المتعلم , ومن أهم السبل إلي ذلك هو تطوير استراتيجيات التدريس وأساليبها بحيث تواكب التقدم العلمي وتعمل علي إثراء العملية التعليمية(وحيد جبران, 2002 م، ص 6وير

إن للطلبة قدرات مختلفة , واهتمامات , ودوافع • إن تقديم تعليم متمايز لهم يعتمد

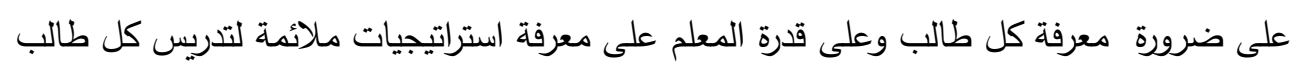

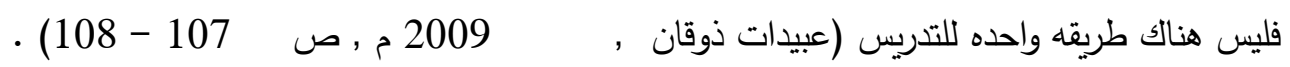
وتمثل التربية الموسيقية ومهاراتها جزء حيوي في التعليم حيث أكد التربوين الموسيقيين علي دورها في تحسين دافعية الطلاب للتعلم وتقوية مهارات الاتصال من خلال تدريبهم ا أثناء دروسها في ممارسة الموسيقي منذ مرحلة رياض الأطفال وما يليها من مراحل تعليمية يسهم بقدر كبير في مساعدتهم علي اكتساب المعلومات والمهارات والمفاهيم والاتجاهات والمواقف التي تؤثر

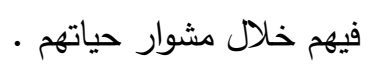
مما لا شك فيه أن هناك مجموعة من التحديات التي تواجه العملية التربوية والتعليمية بشكل عام مثل العولمة والتتافسية والثورة المعلوماتية والتطور العلمي السريع مما يتطلب العمل 
دور إستر اتيجية التعليم المتمايز في زيادة التحصيل الموسيقي لطلاب المرحلة التانوية أ أ منال حسن اسماعيل

علي إيجاد استراتيجيات تعليمية حديثة تعمل علي مواكبة هذه المتغيرات وإدراكا واستجابة لتلك التحديات والمتطلبات ظهر مفهوم التعليم المتمايز الذي نال قدر كبير من الرعاية والاهتمام من قبل الأنظمة التعليمية في الدول المتقدمة حيث ذكرت ( كوثر كوجك ، التدريس بدأت تأخذ مكانتها منذ عام 1990 م في المؤتمر العالمي للتربية الذي عقد في جوميتان وتلاه مؤتمر داكار عام 2000 م 200 أوصي بالتعليم للتميز والتميز للجميع وقد ركزت توصيات تلك المؤتمرات علي الأخذ في الاعتبار

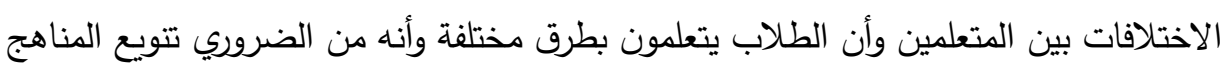

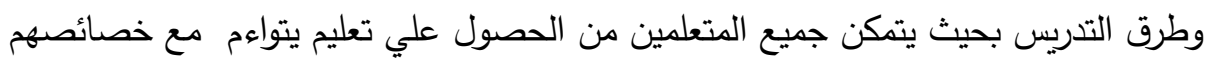
ويحقق لكل منهم أقصي درجات النجاح والانجاز في إطار إمكاناته وقدراته.

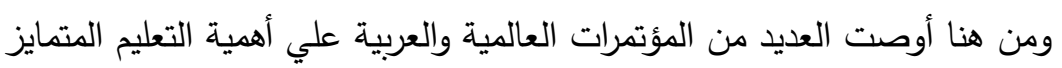
وضرورة تفعيله في المدارس مثل المؤتمر السنوي الرابع والعشرين والمنعقد في مملكة البحرين من 30

ولقد أشارت العديد من الدراسات علي أهمية التعليم المتمايز في تتمية التحصيل مثل :

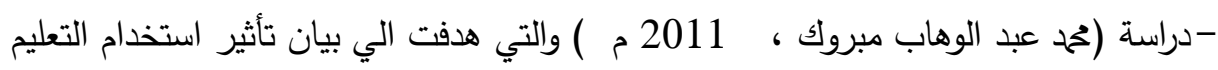

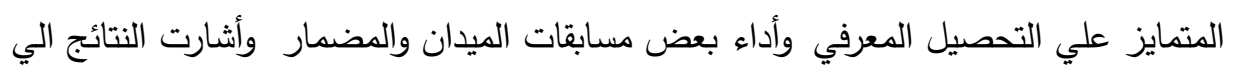
استخدام التعليم المتمايز يؤثر تأثيرا ايجابيا علي التحصيل المعرفي ومستوي أداء بعض

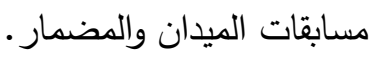
- دراسة ( معيض بن حسن معيض الحليسي , 2012 م ) " اثر استخدام إستراتيجية التعليم المتمايز علي التحصيل الدراسي في مقرر اللغة الانجليزية لدي تلاميذ الصف السفي السادس الابتدائي

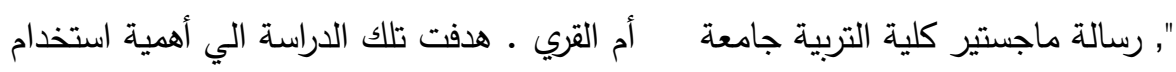

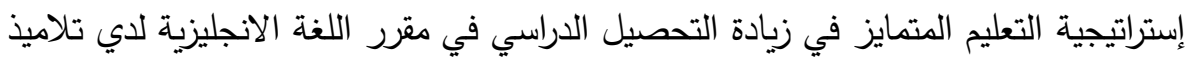

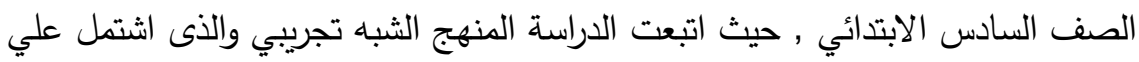

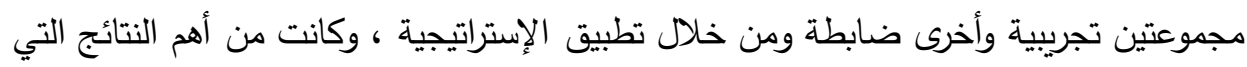
تواصلت لها الدراسة وزيادة وتحسين ملحوظ فى التحصيل الدراسي لهقرر اللغة الإنجليزية لدى لفى لفيل تلاميذ الصف السادس وهذا ما أشارت ليه الدراسة . - دراسة ( وسام عبد القادر الفقهاء ، 2012 ) " تبنى استراتيجية التميز فى التعليم والتعلم ودورها

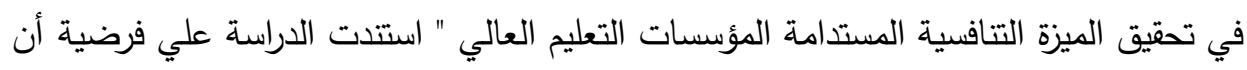
تطوير استراتيجيات التميز فى التعليم التعلم ، وتتفيذها يعتبر متطلبا سابقا مهما حيويا لتحقيق لتئيق 
دور إستر اتيجية التعليم المتمايز في زيادة التحصيل الموسيقي لطلاب المرحلة التانوية أ أ منال حسن اسماعيل

مؤسسات التعليم العالي الميزة التنافسية المستدامة ، وتواصلت الدراسة إلي عدد من النتائج منها أن هناك ارتباطا قويا بين تبنى استراتيجيات التميز في التعليم والتعلم وبين تحقيق مؤسسات

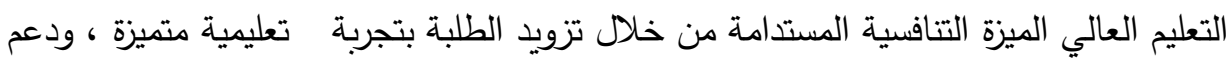

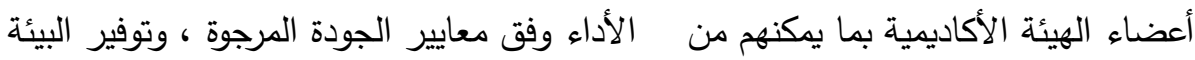

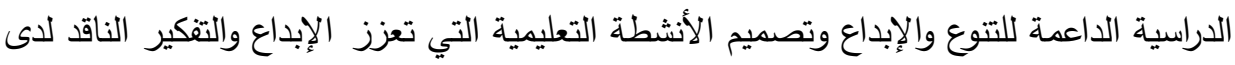

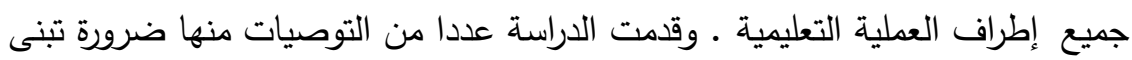

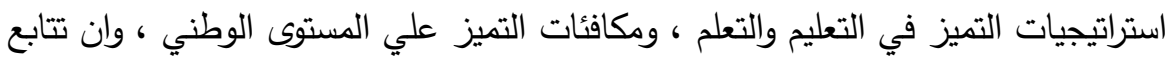

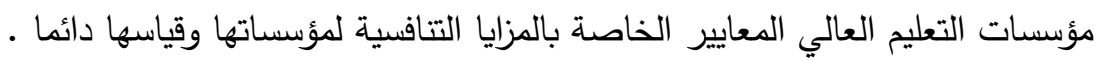

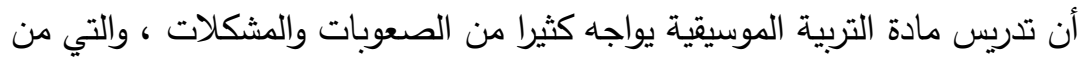

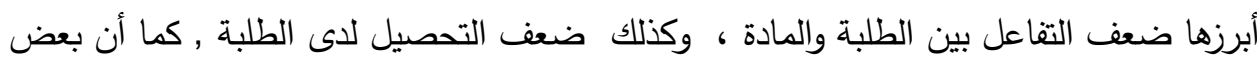
مواضيع التربية الموسيقية بها كثير من القواعد والنظريات ، والتي يجب على ولى المتعلم معرفتها وفهمها لئها

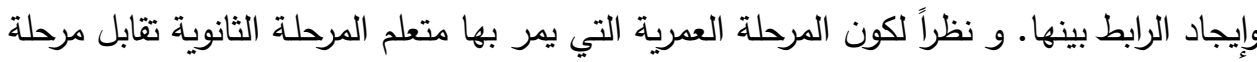

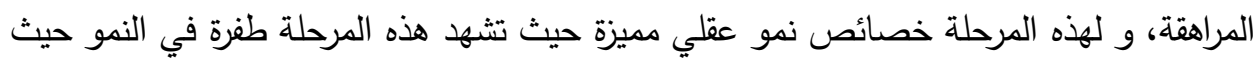

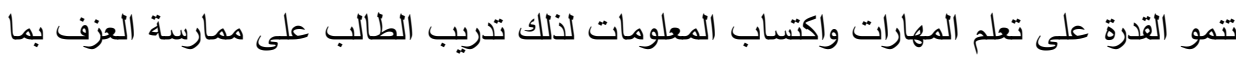
يثغل وقت فراغه بهواية محببة تبعده عن الاستغراق في أحلام اليقظة وتجنبه السلوك الضار تلبكار فينعكس ذلك علي تحصيله ومعرفته . ولهذا تم اقتراح استراتيجية التمايز لتكون أحد المخططات التتظيمية المستخدمة في تدريس ولته

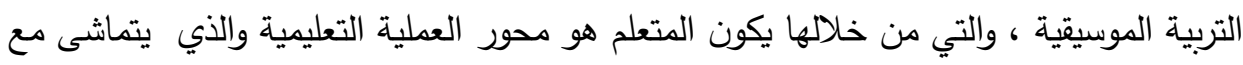

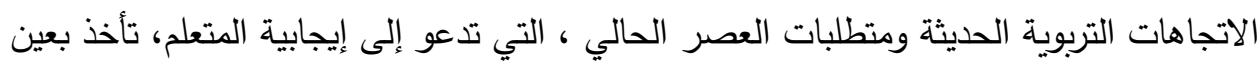

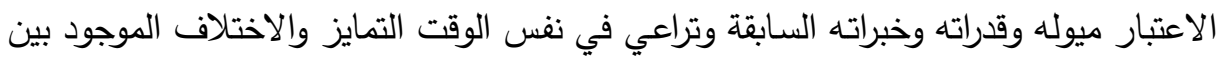
المتعلمين لذلك سوف تعمل الباحثة على تجريب استراتيجية تعليمية تعتبر من أحدث استراتيجيات

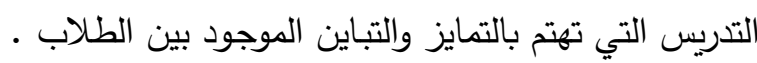

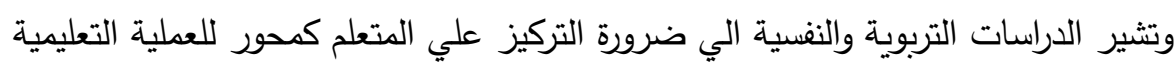
وهذا ما يحققه التدريس المتمايز حيث يركز علي مساعدة كل متعلم أن يحقق أهداف المنهج ويبدأ مع المتعلم من حيث هو · (كوثر كوجك , 2008 م , 75 )

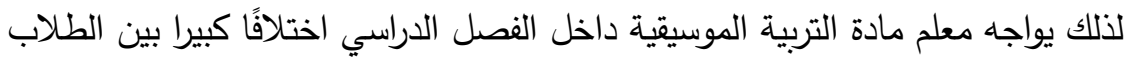

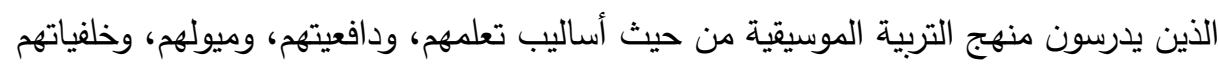

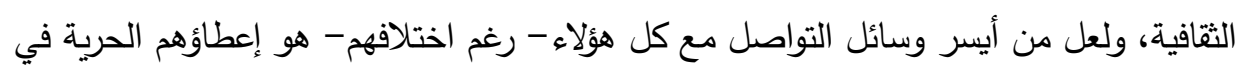
اختيار طريقة التعلم التي تتاسبهم، وهذا يتطلب من المعلم ضرورة استخدام العديد من استراتيجيات 
دور إستر اتيجية التعليم المتمايز في زيادة التحصيل الموسيقي لطلاب المرحلة التانوية أ أ منال حسن اسماعيل

التدريس، ولاحتواء هذا التتوع داخل الفصل الدراسي الواحد ظهر اتجاه حديث في التدريس؛ يسىى التدريس المتمايز أو التدريس المتتوع. والتعليم المتمايز يقوم على إجراء تعديلات في أحد عناصر التدريس)المحتوى أو الإجراءات أو المنتج) وفقًا لمصادر التتوع داخل كل متعلم في الفصل الدراسي من حيث (ميوله أو استعداداته

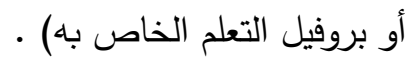

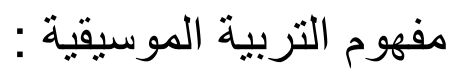

هو ضمان حدوث نمو من نوع مميز عند الفرد من خلال التميز ولتعبير بلغة النغمات والألحان والإيقاع المدروس وألوان التعبير الموسيقى المختلفة التي تعكس الطابع المميز لشخصية

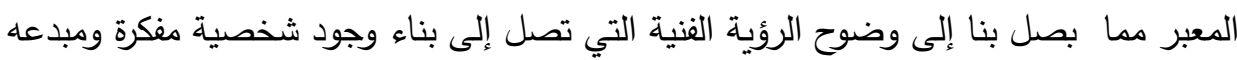

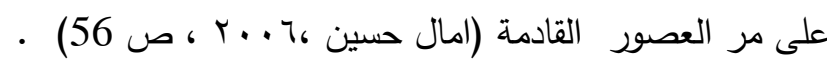

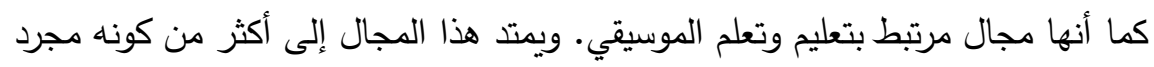

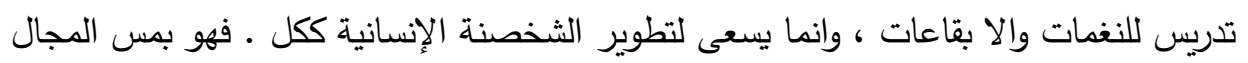

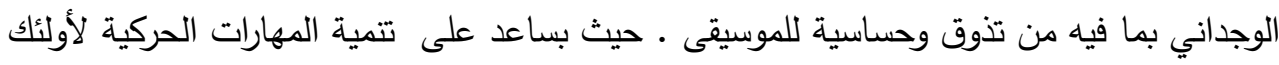

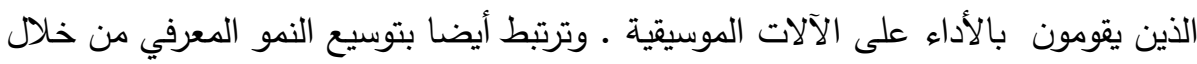

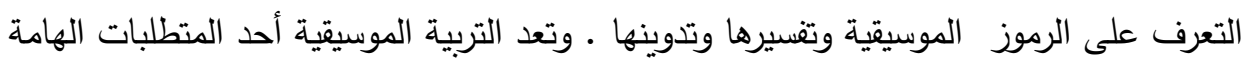

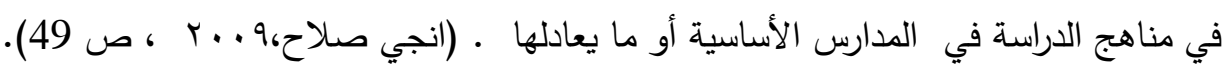

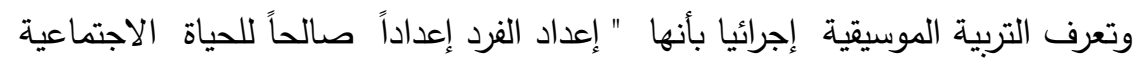

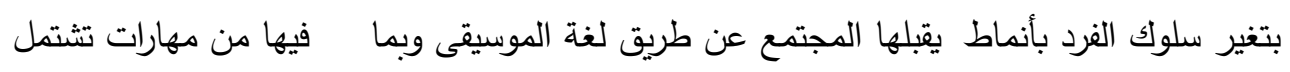
على الغناء و العزف و الإيقاع الحركي والتذوق الفني والارتجال ".

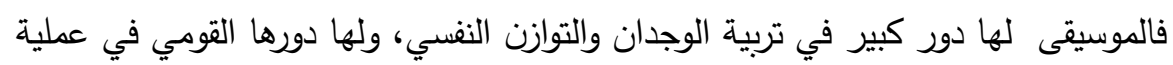

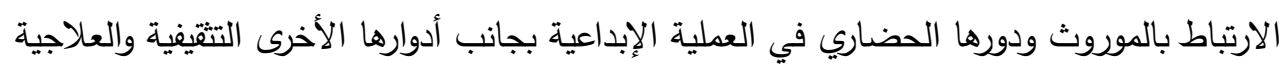

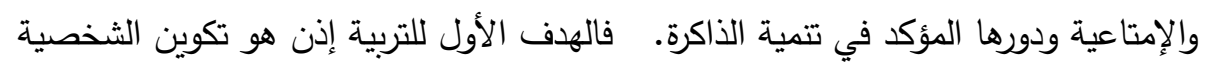

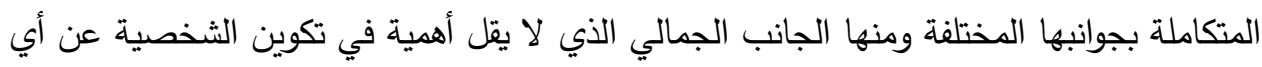

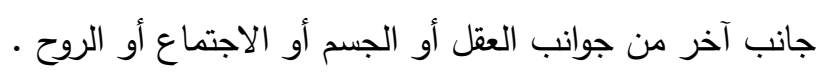

\section{مفهوم التعليم المتمايز :}

هناك مجموعة من التعاريف لمفهوم التعليم التمايز منها " انه يعني تعرف احتياجات

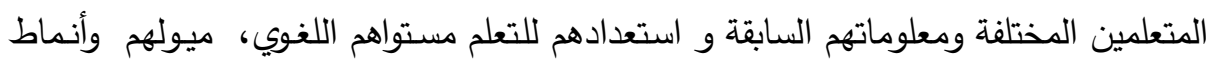


دور إستر اتيجية التعليم المتمايز في زيادة التحصيل الموسيقي لطلاب المرحلة الثانوية أ أ منال حسن اسماعيل

تعلمهم المفضلة، ثم الاستجابة لذلك في عملية التدريس • إذن تتويع التدريس هو عملية تعليم

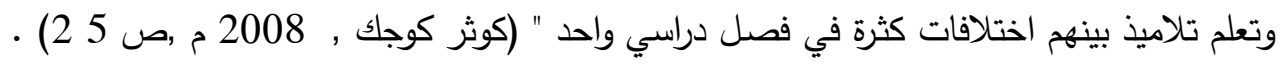

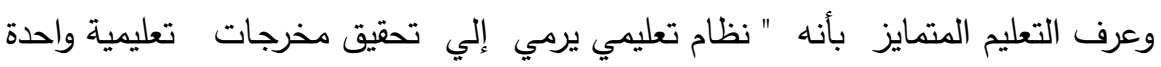

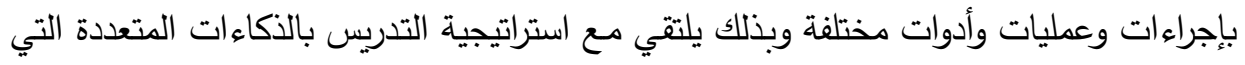

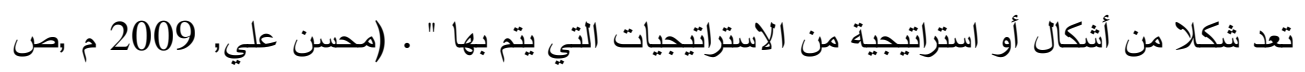

\section{أهمية التعليم المتمايز :}

تظهر أهمية التعليم المتمايز كاستراتيجية تدريس تضمن جودة التعليم الذي فرضته عوامل

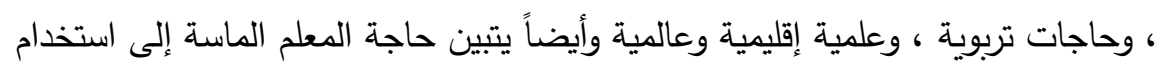
استراتيجيات التعليم المتمايز وهناك فوائد متعددة لذلك نذكر منها :

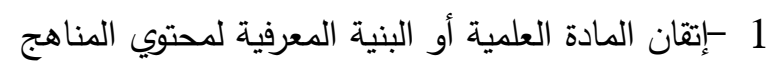

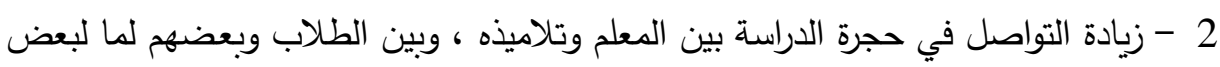

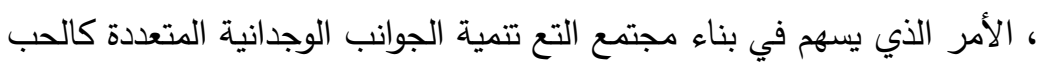

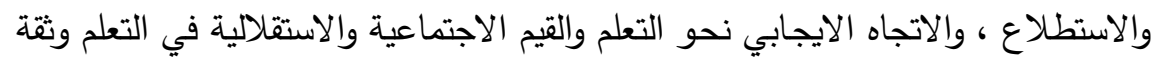
كل من الطالب والمعلم بالنفس والاتجاه الائساب 3 -تتمية الجوانب المهارية لاي كل من الطلاب والمعلمين ، حيث تسمح الاستراتيجيات

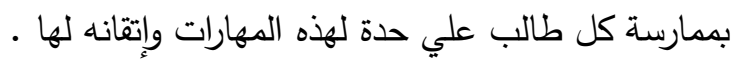
4 5 -تنفيذ المنهج الدراسي وتحقيق أهدافه علي نحو صحيح ( كمال زيتون , 1995 م , ص9

وتتبع أهية التعليم المتمايز من عدة جوانب، ومنها أنه يقوم على مبدأ التعليم للجميع فهو

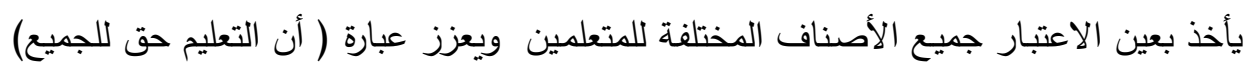

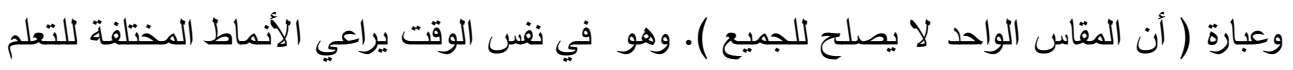

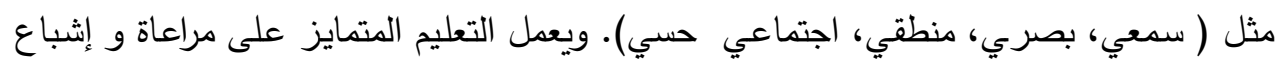

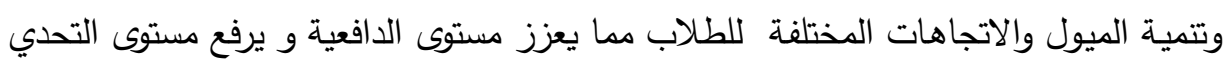

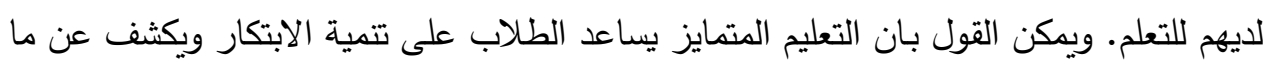
لا ى المتعلمين من إبداعات. 
دور إستر اتيجية التعليم المتمايز في زيادة التحصيل الموسيقي لطلاب المرحلة التانوية

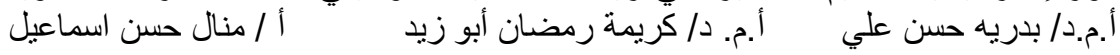

ومما يزيد من أهمية التعليم المتمايز أنه يقوم على التكامل بين الاستراتيجيات المختلفة

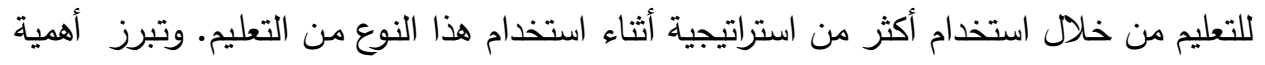

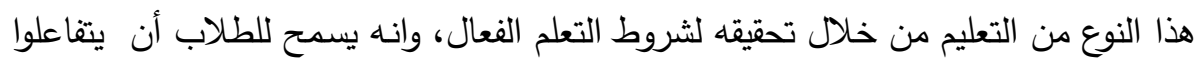

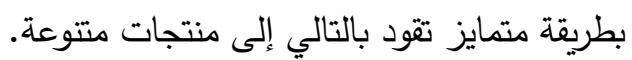

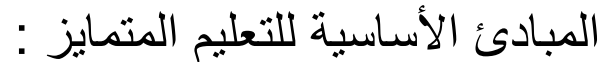

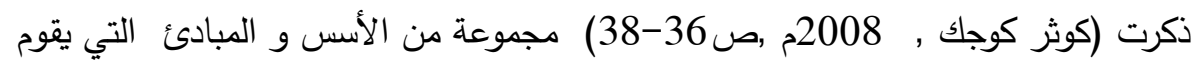
عليها التعليم المتمايز :

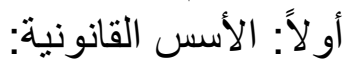

وأهمها ما تتص عليه وثائق حقوق الإنسان من حق كل طفل الحصول على تعليم عالي

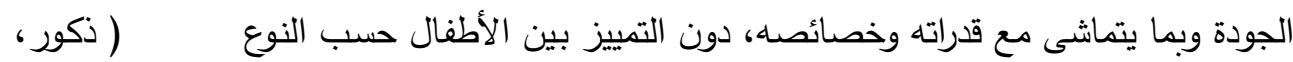

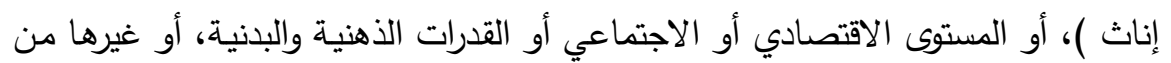
الاختلافات .

وإعمالا لهذا المبدأ أخذ التعليم في بعض الدول العربية بمبدأ أن توفر الدولة كل الإمكانات

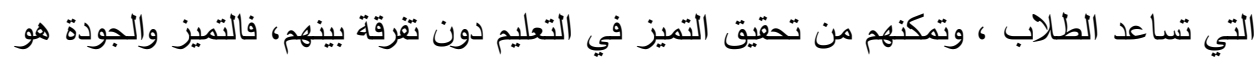
هدف للجميع · لهان تبني استراتيجية التعليم المتمايز على عدد من الأسس النفسية، ومن أهمها ما يلي: 1 - 1 -كل طالب قابل للتعلم، وقادر على التعلم. 2 - الطلاب يتعلمون بطرق مختلفة

3 - الذكاء متنوع ومتعدد الأنواع، ويوجد عند الأفراد بدرجات متفاوتة. 4 - المخ البشري يسعى للفهم والوصول إلى معنى المعلومات التي يستقبلها. 5 - يحدث التعلم بصورة أفضل في حالات التحدي المناسب والمعقول. 6 كيسعى الإنسان دائما للنجاح والتميز . 7 تقبل الاختلافات بين الفرد والآخرين ثالثاً : الأسس التربية: من أهم الأسس التربوية لتتويع التدريس ما يلي: لئي: 1 -المعلم هو منسق وميسر لعملية التعلم وليس ديكتاتورا يعطي الأوامر لتتفذ. 2 - المتعلم هو أهم محاور العملية التعليمية، والتعلم هو الهدف الأساسي للتدريس.

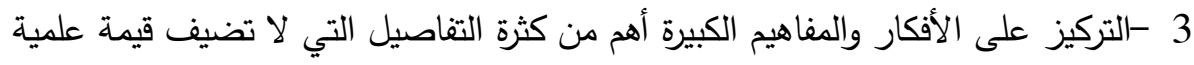
لموضوع التعلم. 
دور إستر اتيجية التعليم المتمايز في زيادة التحصيل الموسيقي لطلاب المرحلة التانوية أ أ منال حسن اسماعيل

4 -التدريس يهدف إلى مساعدة المتعلم على الفهم وتكوين المعني، بمعنى تحويل المعلومات إلى معرفة، ويستطيع المتعلم أن يستخدمها ويوظفها في مواقف متعددة.

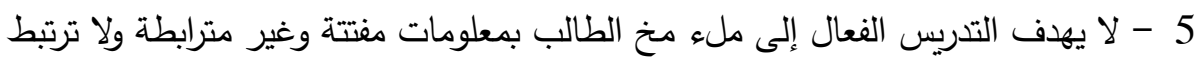

بحياة الطلاب، ثم استدعاء هذه المعلومات في الامتحان كدليل ومؤشر على التعلم

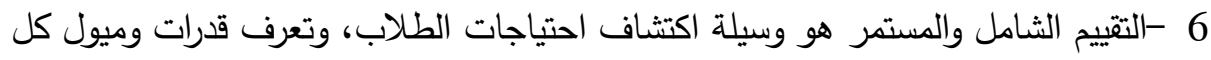
منهم وأنماط تعلمهم وتحديد الاختلافات بينهم لتوجيه التدريس لمواءمة هذه الاختلافات التهات 7 -الفصل الدراسي يمثل مجتمعا بين أفراده اختلافات، ولكنهم يعيشون في تكامل ويتعاملون

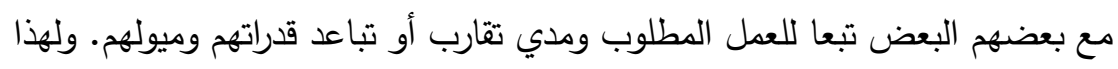

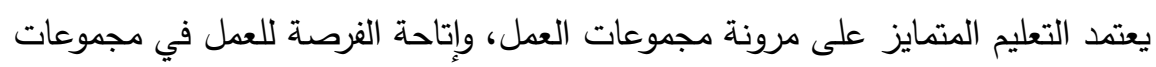
مختلفة أحيانا، أو في ثنائيات أو أفراد أحيانا أخرى.

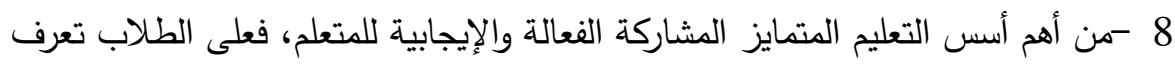

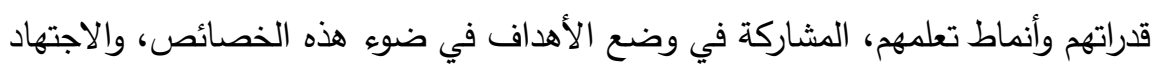

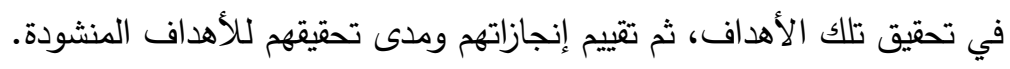

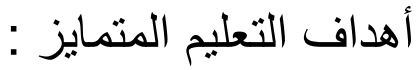
إن أهداف التعليم المتمايز متتوعة مثل: 1 - 1 - تطوير مهات تتسم بالتحدي والاحتواء لكل متعلم .

1. 2 - تطوير أنشطة تعليمية تعتمد على الموضوعات والدفاهيم الجوهرية والعمليات

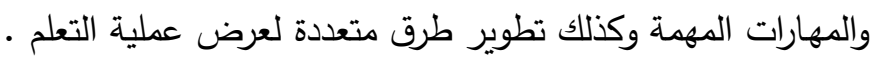
2 -توفير مداخل تتسم بالمرونة لكل من المحتوى والتدريس والمخرجات. 3 -الاستجابة لمستويات الاستعداد لدى الطلاب، والاحتياجات التدريسية والاهتمامات والتفضيلات في عملية التعلم . 4 5 -التوافق مع معايير ومتطلبات المنهج لكل متعلم 6 6 -تكوين صفوف دراسية تشتمل على المتعلم المستجيب والمعلم المسهل • ( 2, 2001 م ,

( Heacox مبررات التعليم المتمايز : للتعليم المتمايز مبررات عدة ذكرتها (كوثر كوجك , 2008 ,ص 53 ) تتمثل فيما يلي : 
دور إستر اتيجية التعليم المتمايز في زيادة التحصيل الموسيقي لطلاب المرحلة التانوية أ أ منال حسن اسماعيل

1 طبيعة الطلاب : وتتمثل في وجود اختلافات متعددة تؤثر في رغباتهم في التعلم وفي قدراتهم على التعلم وعلى سرعتهم على التعلم ، وما يفضلونه من طرق تعليم وتعلم

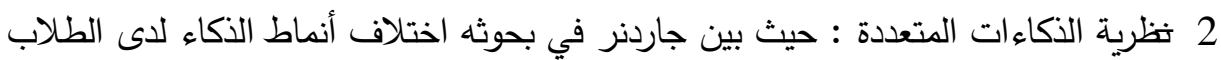

وكذلك اختلاف نسبة وجود النمط الواحد من الذكاء وتصنف الذكاءات المتعددة كما يلي : الذكاء اللفظي اللغوي - ذكاء المنطق الرياضي - الذكاء الحركي - الذكاء الموسيقي - الذكاء

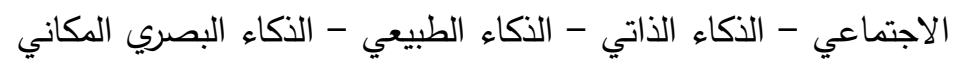
3 4

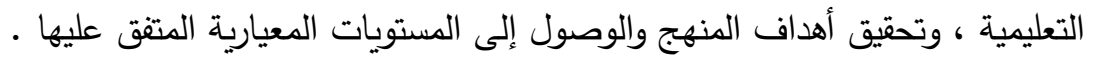

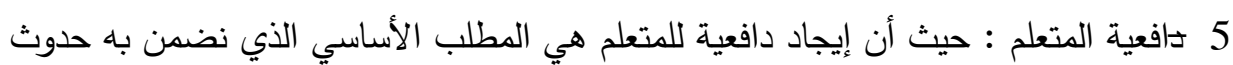
التعلم ومن أسباب التوجه إلى مثل هذا النوع من التعليم ما يلي:

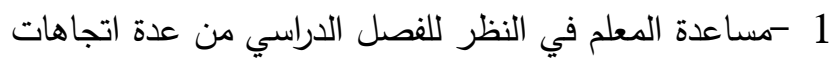
2 - تفهم حاجات ومطالب المتعلمين الفائقين عقلياً 3 - تفهم حاجات و مطالب المتعمين الذين يواجهون صعوبات في التعلم

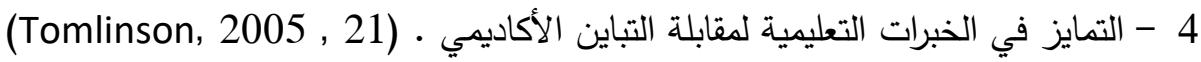

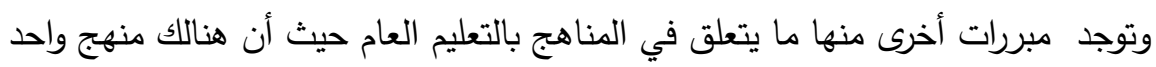
يطبق على جميع الطلاب مما يتطلب تكييف هذا المنهج ليناسب الاحتياجات المختلفة للمتعلمين،

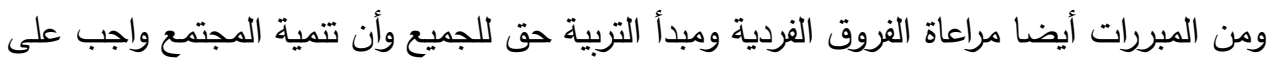
الجميع، و كذلك يساعد التعليم المتمايز على العمل على تحقيق تكافؤ الفرص، والعدالة بين الطلبة ولته

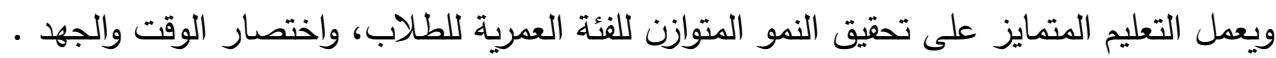

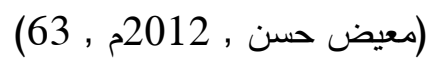

ومن المبررات أيضا مراعاة الفروق الفردية ومبدأ التربية حق للجميع وأن تتمية المجتمع واجب على الجميع. كذلك يساعد التعليم المتمايز على العمل على تحقيق تكافؤ الفرص والعدالة بين

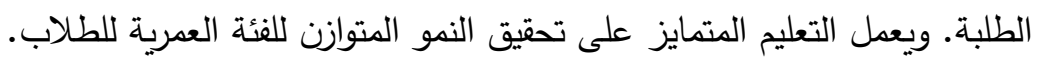

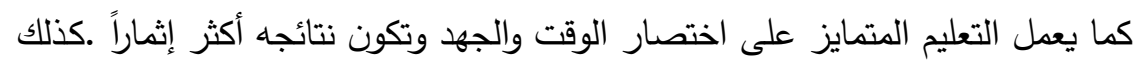
فإننا إذا نظرنا إلى الطلاب نجد أن كل طالب له طابع خاص وطريقة مميزة بالتعلم، وانه لا توجد الته 
دور إستر اتيجية التعليم المتمايز في زيادة التحصيل الموسيقي لطلاب المرحلة التانوية أ أ منال حسن اسماعيل

طريقة تتاسب كل الطلبة. وكذلك فان التعليم المتمايز يمنح كل الطلاب الفرصة للمنفعة المرجوة

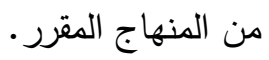

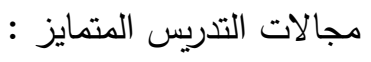

هنالك عدد من المجالات التي تم من خلالها تطبيق التدريس المتمايز كما بين (محسن

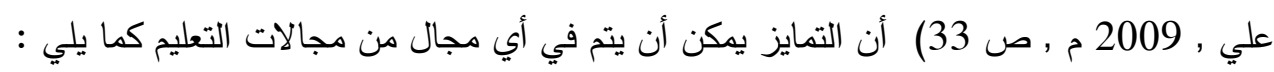

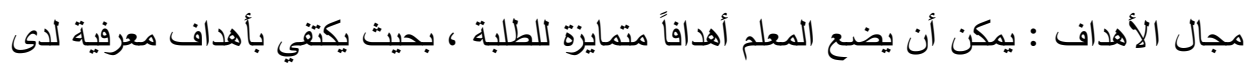
بعض الطلاب، وبأهداف تحليلية لاى آخرين وفي هذا مراعاة للفروق الفردية حسب مستوياتهر الهان العقلية مجال الأساليب : استخدام التمايز بين أساليب التدريس يعد جوهر نظام التعليم الهتمايز إذ يمكن

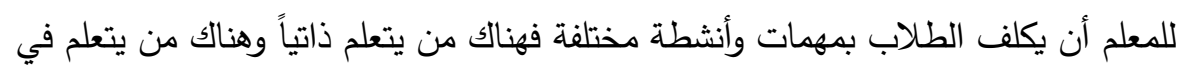

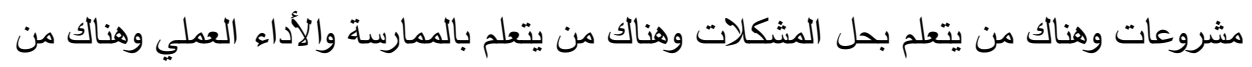
يتعلم بالمناقشة والحوار مجال المخرجات : كأن يكتفي بمخرجات محدودة يحققها بعض الطلاب في حين يطلب من آخرين مخرجات أخرى أكثر عمقاً . مجان

مجال مصادر التعلم : مصادر التعلم عديدة ولكن المتعلمين لا ينجذبون إليها ولا يتفاعلون معها بدرجة واحدة ، لذلك يمكن استخدام التمايز في هذا العنصر من عناصر التدريس عن طريق إغناء

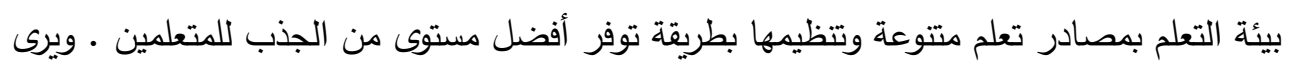
( ثلاثة مجالات أساسية في المنهاج يحتاج المعلمون لأن يربطوا

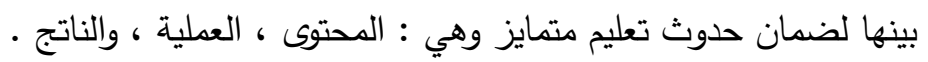

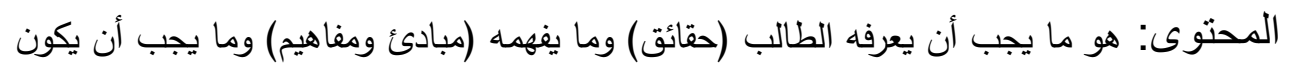
قادراً على عمله (مهارات) وذلك كنتيجة لجزء من مادة تعلمها (درس ، تجربة تعليمية ، وحدة دراسية

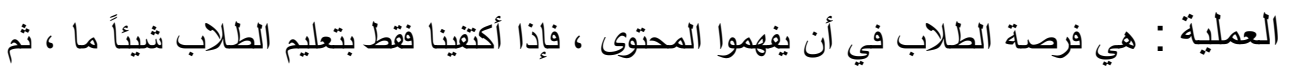

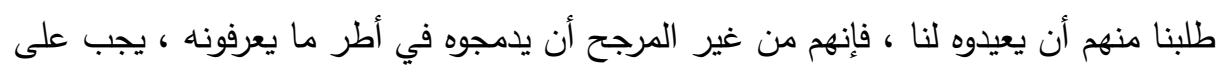

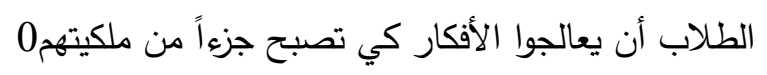
الناتج : هو الوسيلة التي يظهر الطالب من خلالها ما فهمه وما يستطيع أن يعمله كنتيجة لجزء

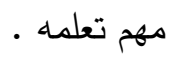
الاستر اتيجيات الفعالة في التعليم المتمايز وهي : 
دور إستر اتيجية التعليم المتمايز في زيادة التحصيل الموسيقي لطلاب المرحلة الثانوية أ أ منال حسن اسماعيل

2- استراتيجية ضغط محتوى المنهج.

4- استراتيجية أنماط التعلم.

6- استراتيجية عقود التعلم - 8

8- استراتيجية حل المشكلات.
1- استراتيجية أركان ومراكز التعلم.

3- استراتيجية الأنشطة المتدرجة.

5- 5 استراتيجية المجموعات المرنة.

7- استراتيجية الأنشطة الثابتة.

9- استراتيجية فكر ، زاوج ، شارك. (كوثر كوجك , 2008 م , ص 1219)

عناصر التدريس التي يمكن إجراء عملية التمايز لها:

أـ المحتوى : Content

Tomlinson \& ويقصد به المعارف والمفاهيم والمهارات التي نريد تعليمها للطلاب :

(Imbeau, 2010, 15

كما يعرف بأنه العناصر المتتوعة التي تثكل المحتوى التدريسي، والتي تثمل الحقائق، والمفاهيم، والتعميمات والمبادئ، والاتجاهات، والمهارات. Ibeneme \& Ireh, 2010, 10)

والمحتوى الفعال هو الذي يتوافق مع تطور نمو الفرد، وفى المدى الذي تسمح بهاه مرحلة

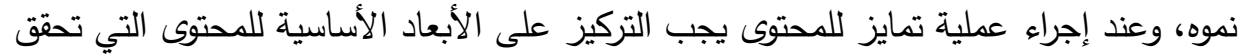

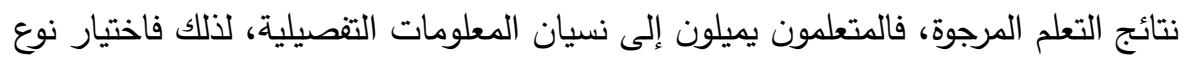

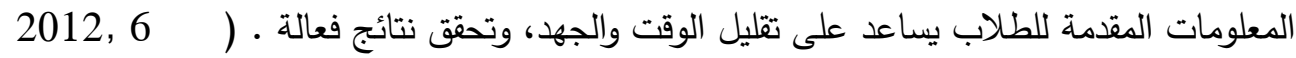

( Pham,

ويمكن إجراء عملية التمايز للمحتوى بعدة طرق، منها:

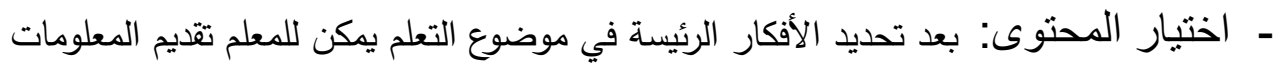

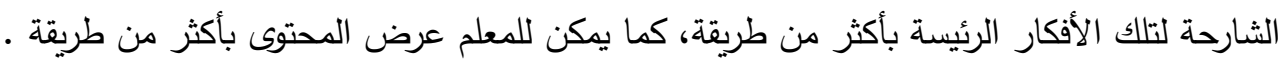
- الوقت اللازم لتعلم المحتوى : يسمح للطلاب بالتعلم بسرعات تتناسب، وقدرات المتعلمين. (كوثر كوجك ، 2008 م ،

- ضغط المحتوى أو إثراؤه : وفيه يتم اختصار بعض المعلومات الموجودة بالمحتوى على ألا

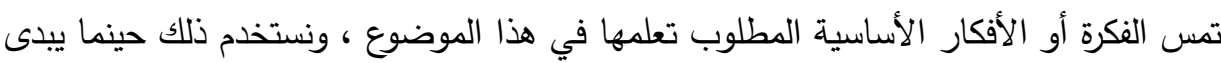

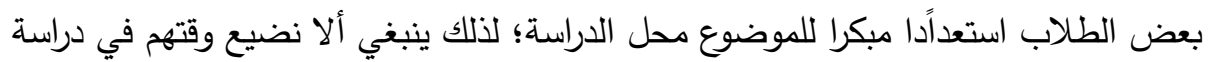
معلومات ومهارات هم بالفعل يتقنونها؛ لذلك فنحن نحاول أن نختصر الجهد في التأكد من إتقانهم

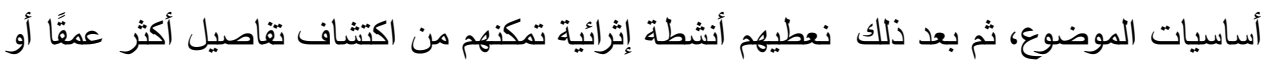
اتساعا حول ذلك الموضوع • Wormeli, 2007, 90) 
- تقديم المحتوى بأثكال مختلفة: حيث يمكن تقديم المواد المقروءة في صورة مستويات قرائية مختلفة، أو نصوص مسجلة، أو تقديم الأفكار في صورة مسموعة ومرئية، أو إعطاء حقائب

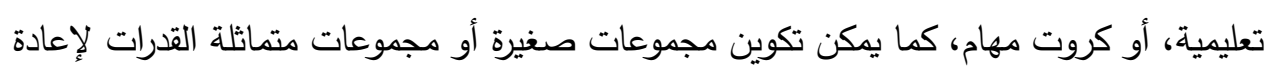

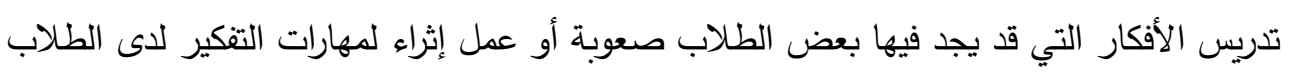

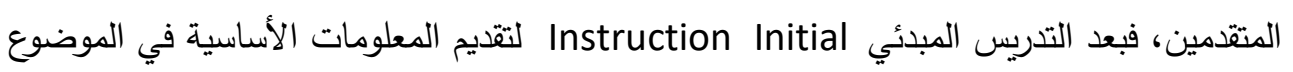

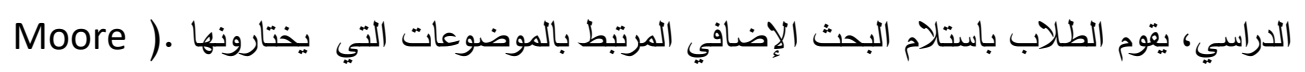

(\& Hansen, 2012, 42

Process: بـ الإجراءات يقصد بها الطريقة التي يتم تعليم المحتوى بها، بمعنى آخر الأنشطة التي تساعد الطلاب

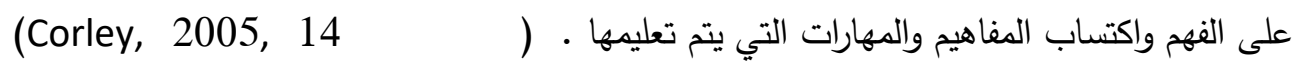

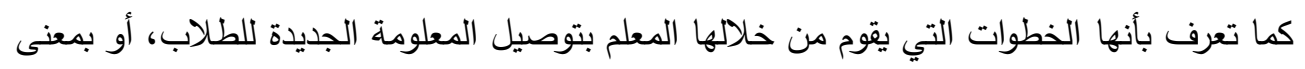

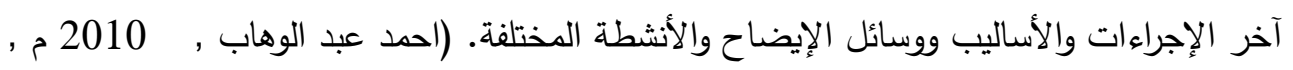

$$
\text { ويمكن إجراء التمايز في الإجراءات عن طريق: }
$$

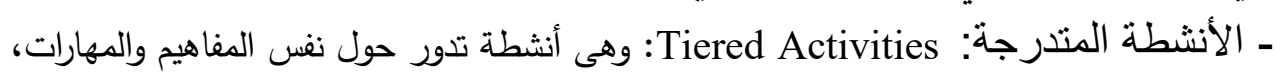
ولكنها تتدرج في مستويات الدعم المقدمة للطلاب أو التعقيد أو التحدي . Bergman , 2006 , 7) (\& Decandido وتستخدم حينما يكون هناك تلاميذ تختلف مستوياتهم المعرفية أو المهارية ويدرسون نفس

المفاهيم ويتعلمون أداء مهارات معينة؛ لذلك يقوم المعلم بتصميم أنشطة متدرجة ومختلفة

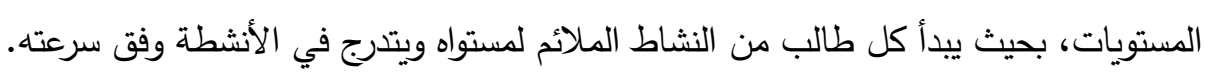

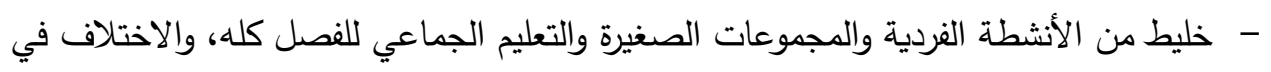

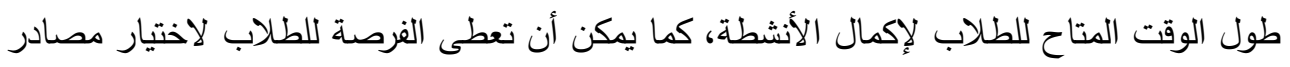
تعلمه الخاصة . (Moore \& Hansen, 2012, 42)

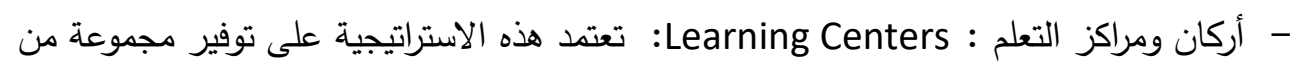
الأركان (الرياضيات- العلوم- القراءة......) ، التي يصممها المعلم بشكل يتوافق مع اهتمامات

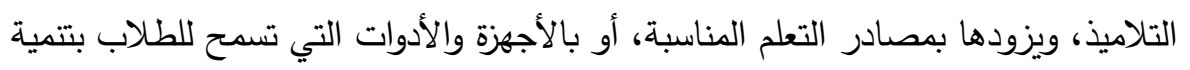

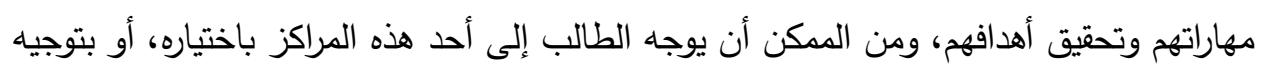

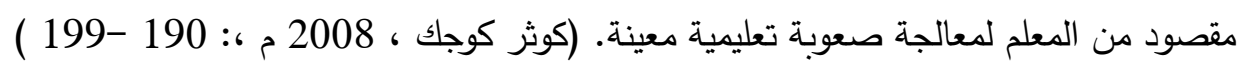
أدوار كل من المعلم والمتعلم والإدارة المدرسية وأولياء الأمور التدريس المتمائة كودية : 
دور إستر اتيجية التعليم المتمايز في زيادة التحصيل الموسيقي لطلاب المرحلة التانوية

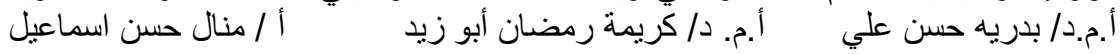

ذكرت (كوثر كوجك ، 2008 م , ص 44 ) أدوار كل من المعلم والمتعلم والإدارة

$$
\begin{aligned}
& \text { المدرسية وأولياء الأمور في التدريس المتمايز وهي : } \\
& \text { أولا: دور المعلم }
\end{aligned}
$$

1 - تعتمد استراتيجية التعليم المتمايز على إيجابية كل من المعلم والمتعلم في الفصل. ويختلف لهن

دور المعلم في فصل التعليم المتمايز عن الفصل التقليدي في كمية وأهمية عمليات

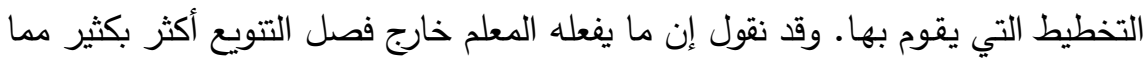

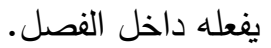

2 - يحاول المعلم تعرف قدرات وميول وأنماط تعلم طلابه، ويعد لذلك الأدوات المناسبة أو

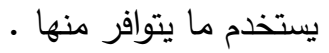

3 - يبدأ التخطيط لتنويع التدريس من أول يوم في الدراسة إن لم يكن قبل الدراسة، فيقوم المعلم

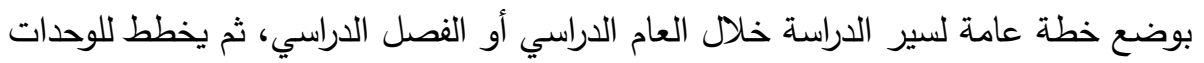

$$
\text { التدريسية ثم للدروس أولا بأول. }
$$

4 - على المعلم الذي يطبق التعليم المتمايز شرح النظرية للتلاميذ ولأولياء الأمور فيشعروا بأنهم

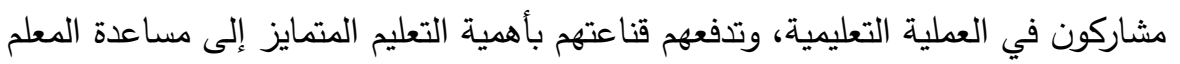

$$
\text { على تحقيق الأهداف المنشودة. }
$$

5 - على المعلم محاولة الا إفادة من زملائه المعلمين والمعلمات وفقا لطبيعة الموقف التعليمي واحتياجات التلاميذ، كما عليه العمل على موافقة القيادات المدرسية والحصول على دعمهر الحن لأنشطة المعلم والمتعلمين في تتويع التدريس. 6 - في أثناء الدروس يقوم المعلم بأكثر من مسئولية فهو ينظم المكان - بمشاركة الطلاب - بما

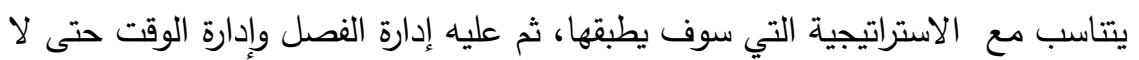
تطغى فترات تتويع التدريس على فترات معاملة الفصل كوحدة متكاملة. وعليه متابعة الطلاب وتقديم المساعدة لمن يحتاجها في الوقت المناسب، وتشجيع الطالب المجته وتوجيه من هو دون ذلك. 7 - على المعلم أن يهتم بتقييم أداء وإنجازات كل طالب، حتى يتعرف احتياجاته، ويتفهم نقاط القوة لاي كل منهم وكذلك نقاط الضعف ليعمل على مواجهتها ومحاولة علاجها. ثنانبا: دور المتعلم أما دور المتعلم في فصول التعليم المتمايز فيتلخص في: 
دور إستر اتيجية التعليم المتمايز في زيادة التحصيل الموسيقي لطلاب المرحلة التانوية أ أ منال حسن اسماعيل

1 - على الطالب أن يفهم ما يدور في الفصل وأهدافه، فمن المهم أن يكون الطلاب على وعي

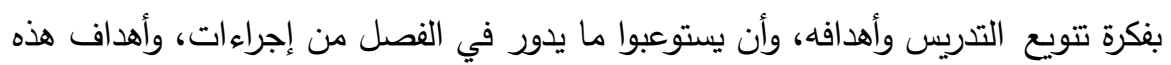

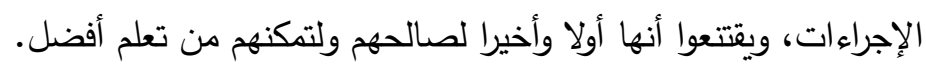

2 - الطلاب في عمليات التعليم المتمايز شركاء إيجابيون عليهم التزامات يجب التئ القيام بهاء

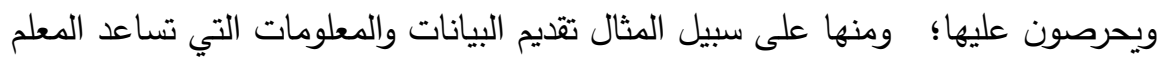

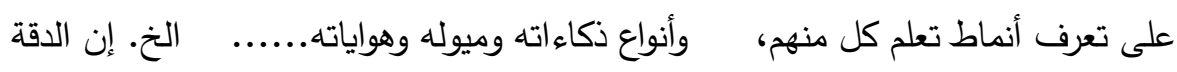

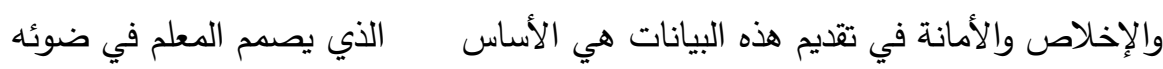
استراتيجيات تدريسه المتتوعة. 3 - على الطلاب أن يتقبلوا فكرة اختلاف المهام والأنشطة التي يقدمها المعلم لبعض منهم، وأن هذا ليس تفضيلا منه للبعض، ولكن هو لمساعدة كل منهم علي تحقيق أقصى درجات

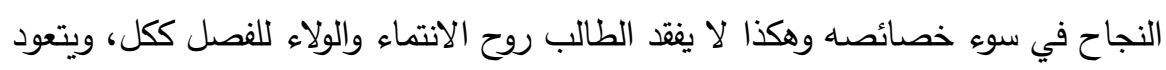

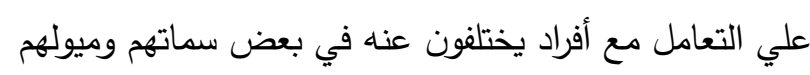
4 - على الطلاب في فصول التعليم المتمايز التعود على كثرة وتتوع عمليات التتييم وأساليبه

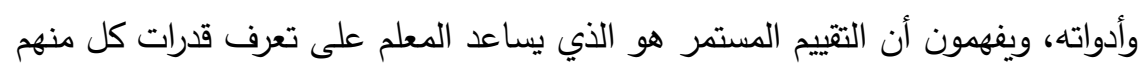
حتى يوجههم التوجيه السليم نحو الأهداف المنشودة.

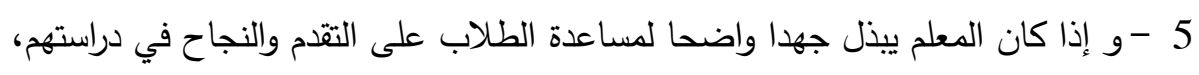

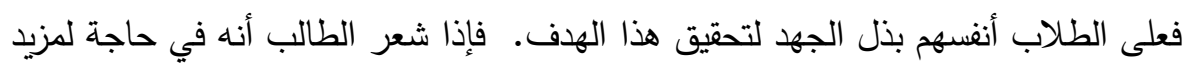

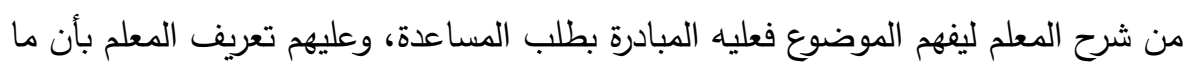

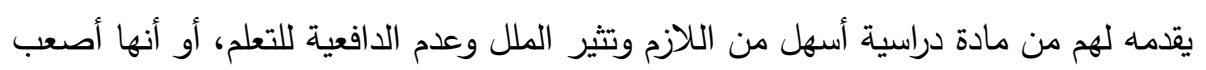

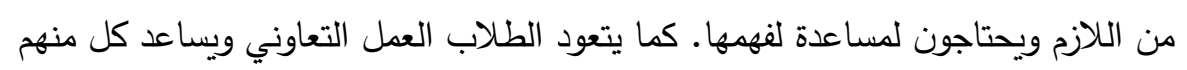

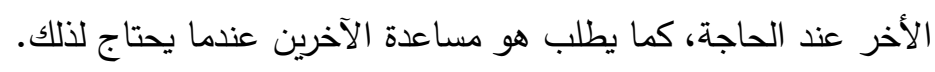

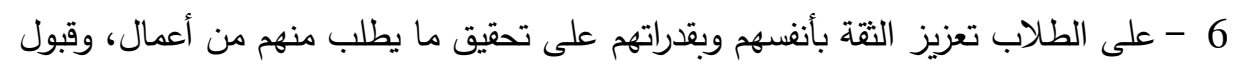

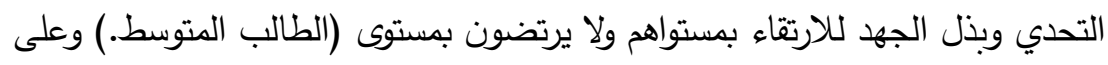

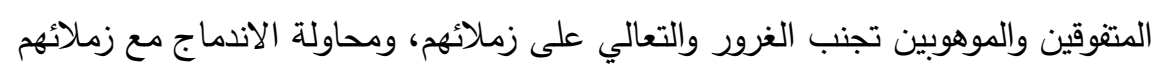
في مختلف الأنشطة والمهام، والعمل على حسن استغلال الوقت وتعظيم فهمهم وإدراكهم للموضوعات المقررة، وعليهم الاستمتاع بما يقدمونه لزملائهم من مساعدة سواء في الأفي الأعمال الفردية أو الجماعية. ثالثا: دور الإدارة المدرسية في التدريس المتمايز 
دور إستر اتيجية التعليم المتمايز في زيادة التحصيل الموسيقي لطلاب المرحلة التانوية أ أ منال حسن اسماعيل

عندما يطلب من المعلمين بتطبيق استراتيجية التعليم المتمايز ، فلابد أن يتوفر لهم

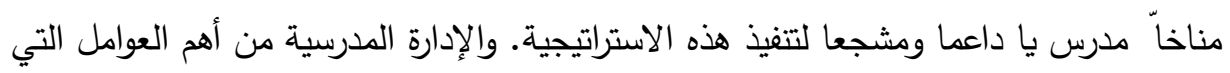

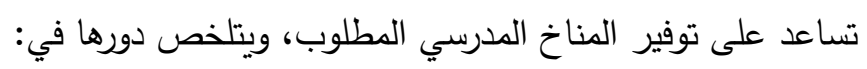

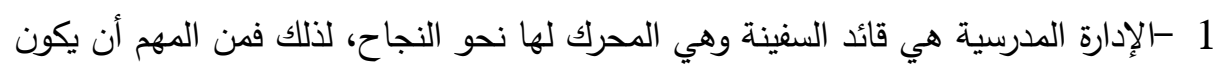
مدير المدرسة على وعي وفهم بنظرية تتويع التدريس، وأهدافها، وكيف تتفذ، ومتطلباتها.

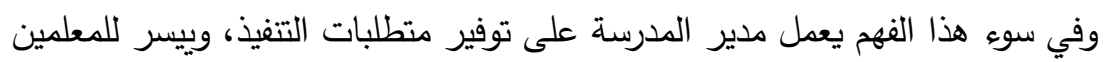
الظروف التي تساعدهم على التطبيق الناجح لتتويع التدريس. ومن ذلك على سلى سبيل المثال استعداده لإحداث بعض التغييرات في شكل الفصل وترتيبه، وفي جدول الحصص التصني المدرسية ليكون أكثر مرونة، وفي توفير مراجع ومصادر متتوعة في الدكتبة المدرسية أو مكتبة الفصل. 2 - سيتطيع القائد أن يشارك المعلمين في مخاطبة أولياء الأمور بشرح ما يحدث مع أبنائهم في

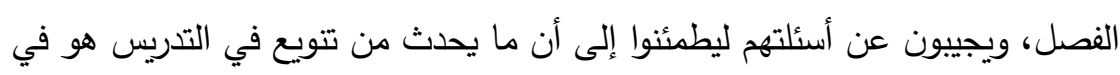
صالح أبنائهم، فيتقبلون الفكرة ويسهمون في العمل على نجاحها.

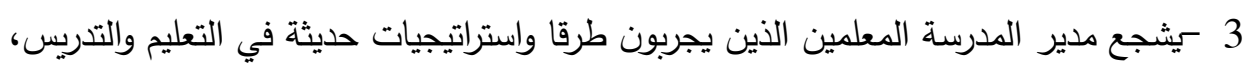
ويعملون على نشر تلك الأفكار بين المعلمين والمعلمات في كافة التخصصات. ولئ وعليه في

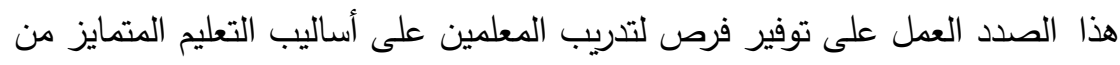

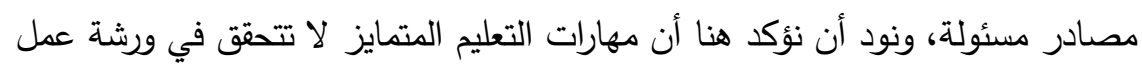
يعقدها الددير بعد اليوم الدراسي...... ولكنها تتطلب برامج تدريبية ددروسة ومخططة

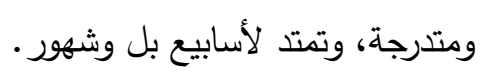

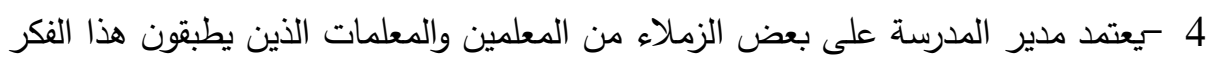

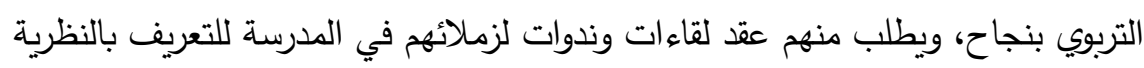

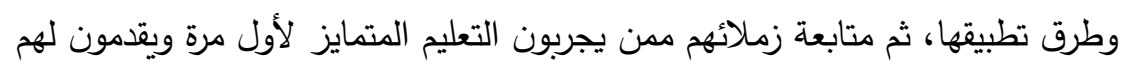
المساعدة والمشورة. 5 - سيتطيع مدير المدرسة أن يوفر فرص البعض المعلمين للالتحاق بالجامعة لدراسة مقرر

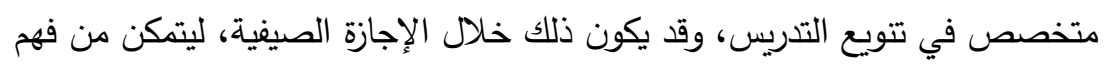
النظرية وتطبيقاتها، ثم ينقل ما تعلمه لزملائه في المدرسة. 
دور إستر اتيجية التعليم المتمايز في زيادة التحصيل الموسيقي لطلاب المرحلة التانوية أ أ منال حسن اسماعيل

6 -من التجارب التي نجحت في مدارس يعص الدول؛ اتفاق مدير المدرسة مع أساتذة من

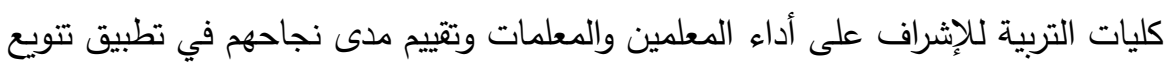
التدريس، وتقديم التوجيهات والإرشادات اللازمة لنجاح التجربة.

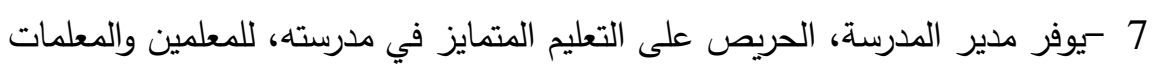

المراجع والنماذج التي يستقيدون منها في فهم النظرية وطرق تلفيذها.

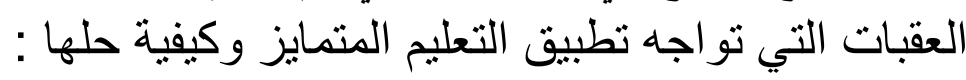

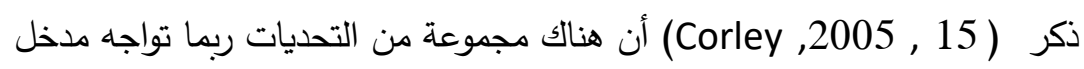

$$
\begin{aligned}
& \text { التعليم المتمايز ؛ تتمثل في: } \\
& \text { أــ الوقت: }
\end{aligned}
$$

التحدي الأكبر لاستخدام مدخل التدريس المتمايز هو الوقت، فالأمر يحتاج إلى وقت

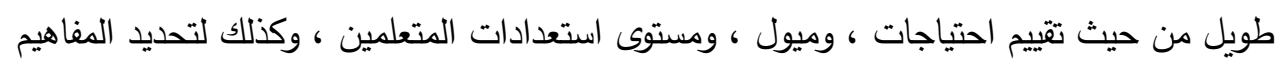

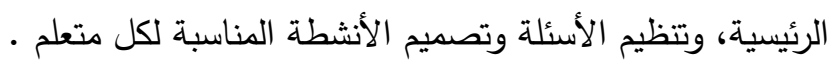

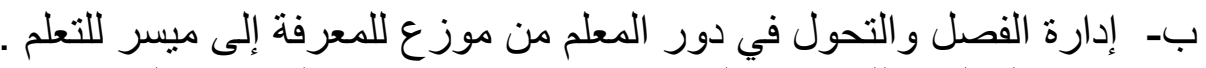

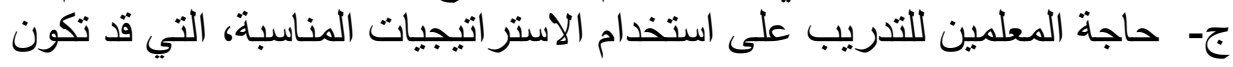
جديدة عليهم.

إن التحدي الذي يواجه المعلم : كيف يُعلم جميع الطلاب ,مع العلم بأن كل طالب

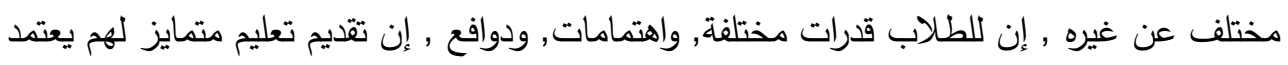

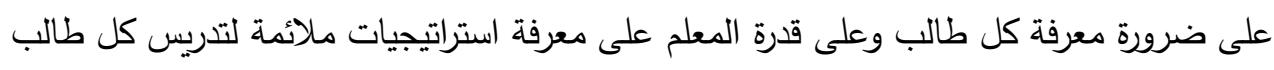

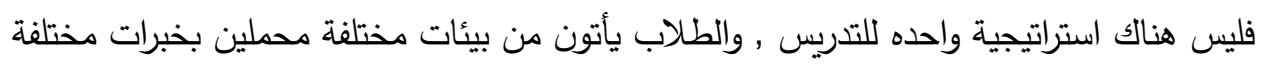

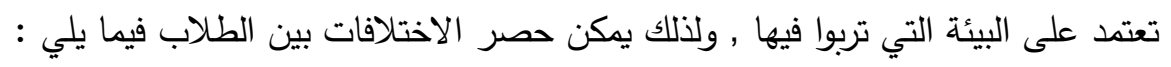

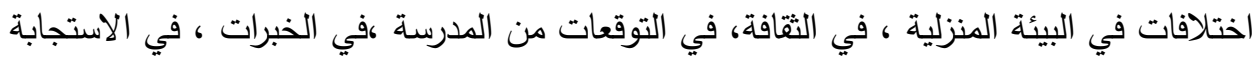

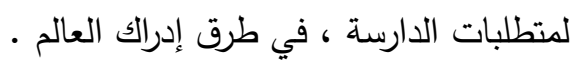
ومن الظلم أن يطلب من المعلم اكتثاف استراتيجية تتاسب كل طالب فالب فالمسألة تتطلب تتظيم الطلاب في مجموعات وتدريس كل مجموعه بالطريقة الملائمة . أن السبيل الوحيد لمعالجة كل هذه المخاوف ، يتم من خلال التطويد بالطريفة الملاثة المهني الفعال للمعلمين الذي يشجعم بقوة على تطبيق تلك المهارات، ثم تقديم التدريب لهم في جميع مراحل عملية التحرك لهول

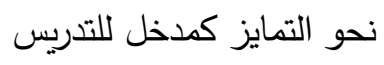

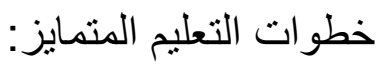
ذكر (خلف حسن محم , 2004 م , ص 33 ) أن خطوات التعليم المتمايز تتحدد في التالي : 
دور إستر اتيجية التعليم المتمايز في زيادة التحصيل الموسيقي لطلاب المرحلة الثانوية أ / منال حسن اسماعيل

1. يحدد المعلم المهارات والقدرات الخاصة بكل طالب محاولاً الإجابة عن السؤالين:

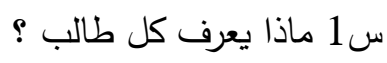

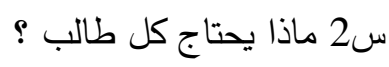

2. إنه بذلك يحدد أهداف الدرس , ويحدد المخرجات المتوقعة ,كما يحدد معايير تقويم مدى هـ

$$
\text { تحقق الأهداف . }
$$

3. يختار المعلم استراتيجيات التدريس الملائمة لكل طالب أو المجموعات لطلبته والتعديلات

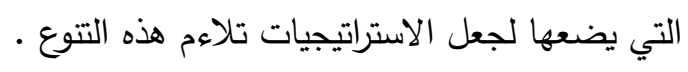

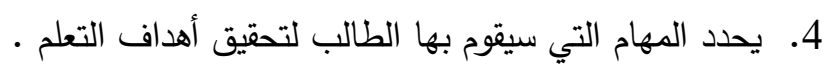




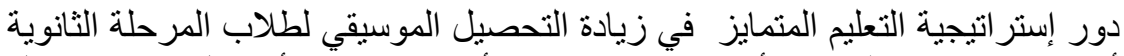
أ أ منال حسن اسماعيل

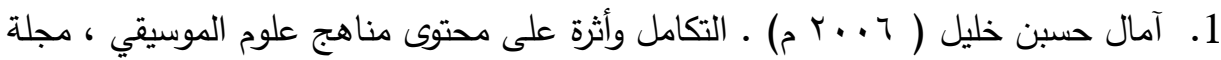

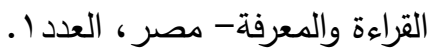

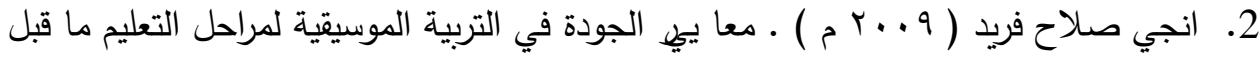

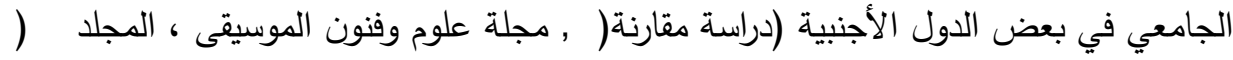

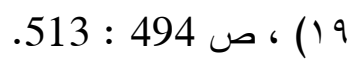

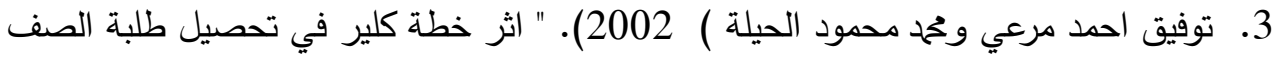

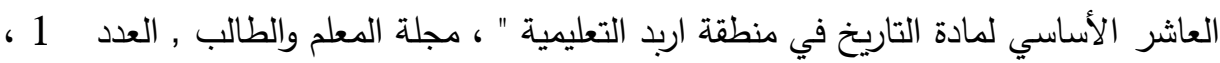
ص 311: 334.

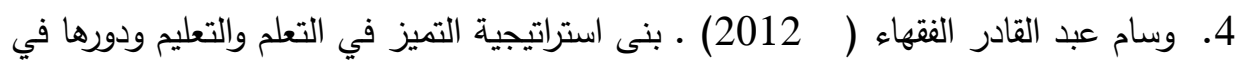

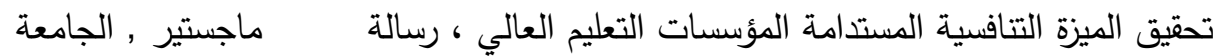

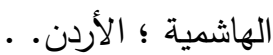

5. كمال حسن زيتون ( 1995) ـ تصنيف الأهداف المدرسية محاولة عربية ، ط 1 ، القاهرة ،

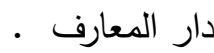
6. كوثر حسين كوجك ( 2002) ـ اتجاهات حديثة في المناهج وطرق التدريس التطبيقات في

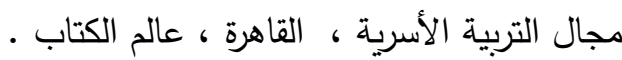

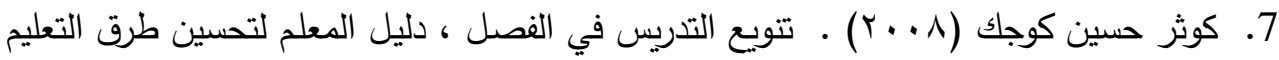
والتعلم في مدارس الوطن العببي, بيروت - مكتب اليونسكو الإقليمي للتربية في الدول العربية

8. محسن علي عطية ( 9 . † ) . الجودة الثاملة والجديد في التدريس ، عمان ، دار صفاء

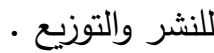

9. محم عبد الوهاب مبروك ( 2011 ) • بيان تأثير استخدام التعليم المتمايز علي التحصيل

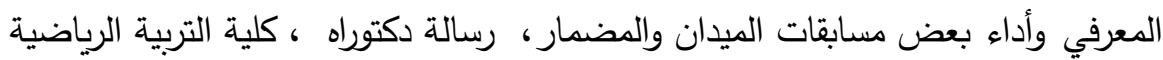
للبنين ، جامعة الإسكندرية .

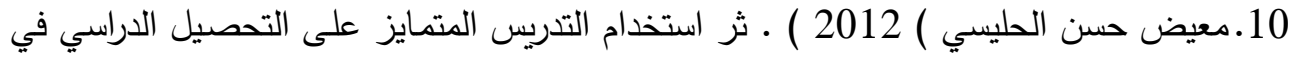
مقرر اللغة الانجليزية لاى تلاميذ الصف السادس الابتدائي ، رسالة ماجستير منشورة ، كلية التئي

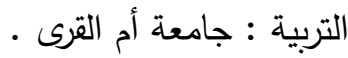

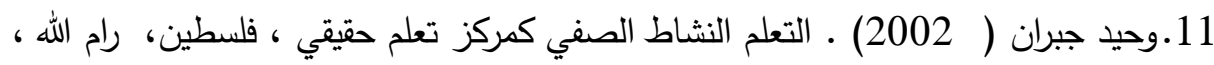

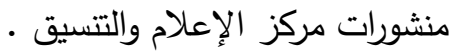


دور إستر اتيجية التعليم المتمايز في زيادة التحصيل الموسيقي لطلاب المرحلة الثانوية

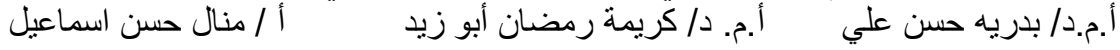

12. Corley, Mary Ann (2005): "Differentiated Instruction Adjusting to the Needs of All Learners" Focus on Basics, Mar., Vol. 7, Issue C, PP.13-16.

13. DeCandido, Helen \& Bergman, Abby (2006): "Differentiation Guide, With Special Emphasis on Grade 3,4 and 5", Putnam/Northern Westchester BOCES, Retrieved (4/2/2014)

14. differentiated_instruction_udl\#.U4a8-HJ_tBQ .

15. Heacox , Diane (2001) Differentiating Instruction in the Regular Classroom; How to reach and teach ALL learners, grades 3-12 by. Free Spirit Publishing.

16. Ireh, Maduakolam \& Ibeneme, Ogo. T. (2010): "Differentiating Instruction To Meet the Needs of Diverse Technical/Technology Education Students at the Secondary School Level", African Journal of Teacher Education Vol. 1, No. 1, PP. 106-114.

17. Moore, Kenneth D. \& Hansen, Jacqueline (2012): Effective Strategies for Teaching in $\mathrm{K}-8$ Classrooms, London: SAGE Publications Ltd. of Ione.

18. Pham, H. L. (2012): "Differentiated Instruction and the Need to Integrate Teaching and Practice". Journal of College Teaching \& Learning, Vol. 9, NO. 1, p. 13:20. Retrieved (5/2/2014) from http://journals.cluteonline.com/index.php/TLC/article/view/ 6710.

19. Tomlinson, Carol Ann \& Imbeau, Marcia B. (2010): Leading and Managing A Differentiated Classroom, Alexandria, Virginia: ASCD.

20. Tomlinson, Carol Ann (2005): "Grading and Differentiation: Paradox or Good Practice?", Theory Into Practice, Vol. 44, Issue 3, PP. 262-269.

21. Wormeli, Rick (2006): Fair isn't Always Equal: Assessing and Grading in the Differentiated Classroom, Portland, Maine: Stenhouse Publishers. 